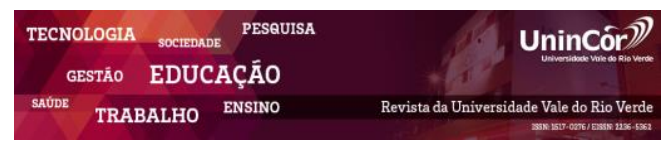

Revista da Universidade Vale do Rio Verde ISSN: 1517-0276 / EISSN: 2236-5362 v. $16 \mid \mathbf{n}^{\circ} .3$ | Ano 2018

Gabriela de Almeida Neri Universidade Vale do Rio Verde (UninCor) gabineri2802@hotmail.com

Alex dos Santos Arci Universidade Vale do Rio Verde (UninCor) alexarci21@gmail.com

Suelem Aparecida Costa Firmiano Universidade Vale do Rio Verde (UninCor) suuh-elen@hotmail.com

Aurivan Soares de Freitas Universidade Vale do Rio Verde (UninCor) aurivan.freitas@unincor.edu.br

Eliana Alcantra Universidade Vale do Rio Verde (UninCor) prof.eliana.alcantra@unincor.edu.br

Ramiro Machado Rezende Universidade Vale do Rio Verde (UninCor) prof.ramiro.rezende@unincor.edu.br

\section{FERTILIZANTE ORGÂNICO COMERCIAL NA REDUÇÃO DO CRESCIMENTO MICELIAL DE \\ Fusarium oxysporum f. sp. lycopersici DO TOMATEIRO}

\title{
RESUMO
}

O tomateiro (Solanum lycopersicum L.) é uma cultura de importância econômica no Brasil e no mundo. A cultura é afetada por diversas doenças. Dentre as principais doenças, destaca-se a murcha de Fusarium, cujo agente etiológico é o fungo Fusarium oxysporum f. sp. lycopersici. Assim, objetivou-se com este trabalho avaliar o efeito de fertilizante orgânico (Xilotrom Gold ${ }^{\circledR}$ ) na redução do crescimento micelial de $F$. oxysporum f. sp. lycopersici no tomateiro. Foram testadas cinco concentrações do produto $\left(0,75,150,300\right.$ e $\left.450 \mu \mathrm{L} \mathrm{L}^{-1}\right)$. Para realizar o ensaio, preparou-se o meio de cultura batata dextrose ágar (BDA) e, em seguida, incorporou-se ao meio as concentrações do produto. Após o preparo, o meio de cultura foi vertido em placas de Petri com $9 \mathrm{~cm}$ de diâmetro. Após solidificação do meio de cultura, foi depositado no centro de cada placa um disco de micélio $(5 \mathrm{~mm}$ de diâmetro) do patógeno. $\mathrm{O}$ experimento foi montado em delineamento inteiramente casualizado com 5 repetições para cada tratamento. As avaliações do crescimento micelial foram transformadas em índice de velocidade de crescimento micelial (IVCM). Observou-se que na testemunha sem aplicação do produto houve maior IVCM, entretanto, com o aumento da concentração do produto, o IVCM foi reduzido de $9,8 \mathrm{~mm}$ na concentração de $75 \mu \mathrm{L} \mathrm{L}^{-1}$ para 0 nas demais concentrações. Portanto, nas concentrações de 150,300 e $450 \mu \mathrm{L} \mathrm{L}^{-1}$ do produto houve inibição completa do crescimento micelial.

Palavras-chave: Solanum lycopersicum L.. Murcha de Fusarium. Xilotrom Gold ${ }^{\circledR}$. Adubação orgânica.

\section{COMMERCIAL ORGANIC FERTILIZER TO REDUCE MYCELIAL GROWTH OF Fusarium oxysporum f. sp. lycopersici OF TOMATO}

\begin{abstract}
Tomato (Solanum lycopersicum L.) is a crop of economic importance in Brazil and in the world. The crop is affected by several diseases. Among the main diseases, we can mention Fusarium wilt, whose etiological agent is the fungus Fusarium oxysporum f. sp. lycopersici. The objective of this work was to evaluate the effect of organic fertilizer (Xilotrom Gold®) on the reduction of the mycelial growth of $F$. oxysporum f. sp. lycopersici in tomato. Five concentrations $(0,75,150,300$ and $450 \mu \mathrm{L} \mathrm{L}^{-1}$ ) were tested. To perform the assay, the potato dextrose agar (PDA) culture medium was prepared and then the product concentrations were incorporated into the medium. After the preparation, the culture medium was poured into $9 \mathrm{~cm}$ diameter
\end{abstract}


Petri dishes. After solidification of the culture medium, a mycelial disc ( $5 \mathrm{~mm}$ diameter) of the pathogen was deposited in the center of each Petri dish. The experiment was set up in a completely randomized design with 5 replicates for each treatment. Mycelial growth assessments were transformed into speed of mycelial growth index (SMGI). It was observed that in the control (without application of the product) there was higher SMGI. However, as the concentration of the product increased, the SMGI was reduced from $9.8 \mathrm{~mm}$ in the concentration of $75 \mu \mathrm{L} \mathrm{L}^{-1}$ to 0 in the other concentrations. Therefore, at the concentrations of 150, 300 and $450 \mu \mathrm{L} \mathrm{L} \mathrm{L}^{-1}$ of the product there was complete inhibition of mycelial growth.

Keywords: Solanum lycopersicum L.. Fusarium wilt. Xilotrom Gold $^{\circledR}$. Organic fertilization.

Recebido em: 04/09/2018 - Aprovado em: 12/11/2018 - Disponibilizado em: 30/12/2018

\section{INTRODUÇÃO}

O tomate (Solanum lycopersicum L.) é uma cultura de importância econômica no Brasil e no mundo. A cultura pertence à família Solanaceae, na qual também fazem parte a batata, a berinjela, a pimenta e o pimentão, sendo a hortaliça mais importante produzida no Brasil, considerando os aspectos socioeconômicos. É considerada uma das espécies mais consumidas em todos os estados do País, por todas as classes sociais e cultivada em diferentes condições climáticas (SIDRA, 2018).

De acordo com dados do IBGE (2018), no ano de 2018 o Brasil produziu 4,2 milhões de toneladas de tomate em 62,6 mil hectares de área plantada, apresentando pequena redução em relação ao ano de 2017 (produção de 4,3 milhões de toneladas em uma área de 64,7 mil hectares).

A cultura é afetada por diversas doenças que podem ser de origem fúngica, bacteriana, virótica ou por nematoides. A maior parte das doenças infecciosas é causada por fungos, que podem contaminar todos os órgãos das plantas.
Entre as doenças mais preocupantes estão aquelas causadas por fungos que atacam o vegetal a partir do sistema radicular, destacandose a murcha de Fusarium, causada pelo fungo Fusarium oxysporum f. sp. lycopersici, divididos em três raças. As raças 1 e 2 são distribuídas de forma vasta pelo mundo, já a raça 3 apresenta distribuição mais restrita (REIS, 2006).

A identificação correta da doença e o conhecimento a respeito de sua epidemiologia são indispensáveis para se obter medidas de manejo. A diagnose feita de forma errônea pode levar às medidas de controle ineficientes, o que pode provocar perdas na produção (REZENDE et al., 2011).

O tratamento baseado em produtos alternativos pode ser empregado no controle do fungo $F$. oxysporum f. sp. lycopersici. Um exemplo de produto alternativo é o Xilotrom Gold $^{\circledR}$, um fertilizante orgânico composto à base de extratos vegetais de espécies cítricas, extratos vegetais à base de soja, tensoativos e água, que pode ser utilizado para redução do crescimento micelial e da germinação de conídios do fungo. 
Esse é um produto que propõe fortalecer e fortificar o sistema radicular da planta, em função da presença de substâncias promotoras de desenvolvimento radicular, geradas durante o processo de fermentação, não afetando o metabolismo da planta, assim, permitindo melhor desenvolvimento das suas raízes (ARVENSIS, 2018).

Diante do exposto, este trabalho pretendeu avaliar o efeito do fertilizante orgânico Xilotrom Gold $^{\circledR}$ no crescimento micelial de $F$. oxysporum f. sp. lycopersici no tomateiro.

\section{MATERIAL E MÉTODOS}

O ensaio foi conduzido em condições in vitro nos Laboratórios de Microbiologia e de Pesquisa I da Universidade Vale do Rio Verde (UninCor), campus Três Corações-MG, durante o período de 15 de março a 30 de março de 2018.

\subsection{Obtenção do isolado e montagem do ensaio}

O fungo Fusarium oxysporum f. $\mathrm{sp}$ lycopersici foi obtido a partir de plantas de tomateiro da cultivar Débora Victory $\left(\right.$ SAKATA $^{\circledR}$ ) exibindo sintomas de murcha.

$\mathrm{O}$ isolamento foi realizado a partir de fragmentos retirados do caule, entre áreas sadias e afetadas (limítrofes). Os fragmentos foram desinfestados em álcool $70 \%$ por 1 minuto, hipoclorito de sódio a $2 \%$ durante 2 minutos e lavados três vezes em água destilada e esterilizada. Após essa etapa, foram transferidos para placa de Petri contendo meio de cultura batata dextrose ágar (BDA).
O meio de cultura foi preparado utilizando 20g de Ágar-Ágar, 39,5g de BDA e 1.000 mL de água destilada. O meio foi autoclavado durante 30 minutos à $120^{\circ} \mathrm{C}$. As placas foram incubadas em estufa incubadora (BOD), a $25{ }^{\circ} \mathrm{C}$ e fotoperíodo de 12 horas.

$\mathrm{O}$ experimento foi instalado no dia 23 de março de 2018. Foram testadas cinco concentrações do fertilizante orgânico Xilotrom $\operatorname{Gold}^{\circledR}\left(0,75,150,300\right.$ e $\left.450 \mu \mathrm{L} \mathrm{L}^{-1}\right)$. Para a montagem do ensaio, preparou-se o meio de cultura BDA nas concentrações descritas e, em seguida, incorporou-se ao meio as doses do produto. Após o preparo, o meio de cultura foi vertido em placas de Petri de $9 \mathrm{~cm}$ de diâmetro. Após a solidificação do meio de cultura, foi depositado no centro de cada placa um disco de micélio (5 $\mathrm{mm}$ de diâmetro) do patógeno. $\mathrm{O}$ experimento foi montado em delineamento inteiramente casualizado com 5 repetições para cada tratamento. As placas contendo os tratamentos foram incubadas à $25^{\circ} \mathrm{C}$ e fotoperíodo de 12 horas em BOD.

\subsection{Avaliação do crescimento micelial e análise estatística}

As avaliações foram realizadas diariamente, durante seis dias, medindo-se o diâmetro das colônias em dois sentidos opostos, com auxílio de paquímetro. $\mathrm{O}$ índice de velocidade de crescimento micelial (IVCM) foi calculado pela fórmula proposta por Maguire (1962) e adaptada por Oliveira (1991): IVCM = $\sum(\mathrm{D}-\mathrm{Da}) / \mathrm{N}$, em que IVCM = índice de velocidade de crescimento micelial; $\sum=$ somatório; $\mathrm{D}=$ diâmetro médio atual; $\mathrm{Da}=$ 
diâmetro médio do dia anterior e N=número de dias após a deposição do micélio. Os dados foram submetidos à análise de variância e, em caso de significância, foi realizada análise de regressão. As análises foram realizadas utilizando o programa estatístico Sisvar (FERREIRA, 2011).

\section{RESULTADOS E DISCUSSÃO}

Houve interação significativa e as concentrações foram submetidas ao ajuste de modelos. Entretanto, nenhum modelo foi favorável para a descrição do comportamento da variável. Assim, os dados foram submetidos a análise de variância, e quando significativos foram submetidos ao teste de Scott-Knott a 5\% de probabilidade. No tratamento controle (sem aplicação do produto) houve maior índice de velocidade de crescimento micelial (IVCM) apresentando valor de $12,58 \mathrm{~mm}$ por dia. Entretanto, à medida que se aumentou a concentração do produto o IVCM foi reduzido de $9,8 \mathrm{~mm}$ por dia na concentração de $75 \mu \mathrm{L} \mathrm{L}^{-1}$ para 0 nas concentrações subsequentes (Figura $1)$.

Com base nos resultados, entende-se que é desnecessário o uso de doses superiores a $150 \mu \mathrm{L}$ $\mathrm{L}^{-1}$, culminando com maiores gastos com a compra do produto.

Resultados semelhantes aos observados no controle do crescimento micelial de $F$. oxysporum f. sp. lycopersici foram relatados por Cruz et al. (2011) que utilizaram o produto comercial Ecolife $40^{\circledR}$, que também é um fertilizante foliar orgânico a base de extratos vegetais de cítricos, o qual inibiu significativamente o crescimento micelial in vitro do fungo. Segundo o autor, a redução do crescimento micelial de patógenos utilizando produtos à base de biomassa cítrica também foi observada por vários pesquisadores.

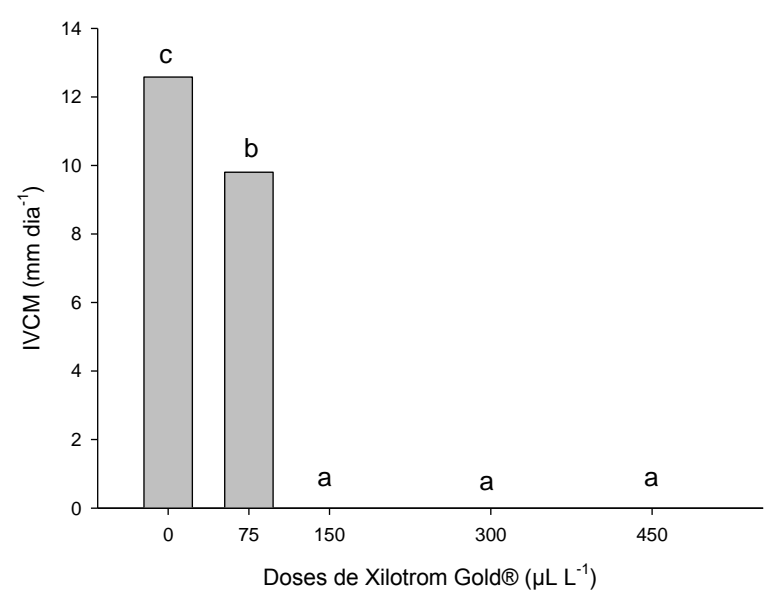

Figura 1. Índice de crescimento micelial (IVCM) de Fusarium oxysporum f. sp. lycopersici em meio de cultura com diferentes doses de Xilotrom Gold ${ }^{\circledR}$. Médias seguidas pela mesma letra não diferem estatisticamente entre si pelo teste de Scott-Knott $(\mathrm{p}<0,05)$. Coeficiente de variação (C.V) $=12,81 \%$.

Cavalcanti et al. (2006) investigaram a

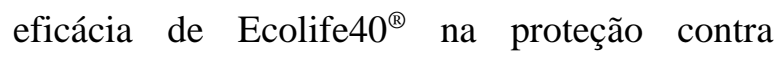
Xanthomonas vesicatoria em tomateiro, tendo como resultado a inibição do crescimento da bactéria em condições in vitro.

Silva (2007) avaliaram o efeito do Ecolife $40^{\circledR}$ no desenvolvimento de $F$. oxysporum f. sp. cubense e os resultados encontrados sugerem que o uso desse fertilizante tem efeito positivo no controle do fungo e pode ser uma alternativa no seu manejo.

A utilização de produtos à base de extratos vegetais é vista como uma nova tecnologia que pode ser repassada para pequenos produtores, diminuindo o uso de fungicidas convencionais, auxiliando assim na preservação 
do meio ambiente e na proteção da saúde dos trabalhadores.

\section{CONCLUSÃO}

O fertilizante Xilotrom Gold ${ }^{\circledR}$ é eficaz na redução do crescimento micelial de $F$. oxysporum f. sp. lycopersici do tomateiro em meio de cultura na concentração de $75 \mu \mathrm{L} \mathrm{L}^{-1}$. Nas concentrações de 150, 300 e $450 \mu \mathrm{L} \mathrm{L}^{-1}$ é eficaz na inibição completa do crescimento micelial.

\section{REFERÊNCIAS}

ARVENSIS. Xilotrom. Disponível em: <https://www.arvensis.com/es/eco-logic/xilotr om/id/149>. Acesso em 08 de março de 2018.

CAVALCANTI, F. R.; RESENDE, M. L. V.; ZACARONI, A. B.; RIBEIRO JÚNIOR, P. M.; COSTA, J. C. B; SOUZA, R. M. Acibenzolar-Smetil e Ecolife $\AA$ na indução de respostas de defesa do tomateiro contra a mancha bacteriana (Xanthomonas vesicatoria). Fitopatologia Brasileira, v.31, n.4, p.372-380, 2006.

CRUZ, S. M. C.; RODRIGUES, A. A. C.; COELHO, R. S. B.; SARDINHA, D. H. S. Ação indutora de produtos abióticos na resistência de tomateiro e efeito sobre o crescimento micelial de Fusarium oxysporum f. sp. lycopersici. Idesia (Arica), v.29, n.2, p.111-118, 2011.

FERREIRA, D. F. SISVAR: a computer statistical analysis system. Revista Ciência \& Agrotecnologia, v.35, n.6, p.1039-1042, 2011.

INSTITUTO BRASILEIRO DE GEOGRAFIA E ESTATÍSTICA - IBGE. SIDRA. Tomate. Disponível em: <https://sidra.ibge.gov.br/ tabela/1618\#resultado> Acesso em: 14 nov. 2018.

REIS, A.; BOITEUX, L. S.; URBEM, A.; COSTA, H. Estabelecimento e caracterização a nível de raça de uma coleção de isolados Fusarium oxysporum f. sp. lycopersici. Brasília: Embrapa Hortaliças, 2006, 14 p.
REZENDE, J. A. M.; MASSOLA, J. R., N. S.; BEDENDO, I. P.; KRUGNER, T. L. Conceitos de doença, sintomatologia e diagnose. In: AMORIM, L. A.; REZENDE, J. A. M.; BERGAMIN FILHO, A. (Eds.) Manual de Fitopatologia: princípios e conceitos. Piracicaba: Ceres, v.1. 2011. p.37- 58.

SIDRA - Sistema IBGE de recuperação automática. Disponível em: <http://www.sidra.ibge.gov.br/bda/tabela/protabl $. \operatorname{asp} ? \mathrm{c}=1618 \& \mathrm{z}=\mathrm{t} \& \mathrm{o}=26 \& \mathrm{i}=\mathrm{P}>$. Acesso em 20 de março de 2018.

SILVA, J. C. Uso de óleos essenciais, extratos vegetais e indutores de resistência no controle alternativo do mal-do-panamá da bananeira. Dissertação de mestrado. Rio Largo, AL. Universidade Federal de Alagoas, 2007.

\begin{tabular}{l}
\hline Gabriela de Almeida Neri \\
Graduanda em Agronomia, Universidade Vale do Rio \\
Verde (UninCor) \\
\hline \\
\hline Alex dos Santos Arci \\
Graduando em Agronomia, Universidade Vale do \\
Rio Verde (UninCor) \\
\hline
\end{tabular}

Suelem Aparecida Costa Firmiano

Graduanda em Agronomia, Universidade Vale do Rio Verde (UninCor)

Aurivan Soares de Freitas
Professor, Universidade Vale do Rio Verde
(UninCor)

Eliana Alcantra
Professora, Universidade Vale do Rio Verde
(UninCor)

\begin{tabular}{l}
\hline Ramiro Machado Rezende \\
Professor, Universidade Vale do Rio Verde \\
(UninCor)
\end{tabular}

